[Aus dem hygienischen Institut der Universität Breslau.]

\title{
Die Filtration bacterientrüber und eiweisshaltiger Flüssigkeiten durch Kieselguhrfilter.
}

$$
\text { Von }
$$

Dr. H. Bitter,

Assistenten am hygienischen Institut zu Breslau.

Die ausgezeichneten Filtrationsleistungen der ron Dr. Nordtme yer beschriebenen Kieselguhrfilter ${ }^{1}$ forderten zu Versuchen darüber auf, ob sich etwa auch stark bacterientrübe und besonders eiweisshaltige Flüssigkeiten mittels dieser Filter mühelos keimfrei filtriren liessen. Ich benutzte zu diesen Versuchen Filterkörper, welche mit metallenen Kopfstücken, ähnlich denen der Chamberlandkerzen, versehen waren. In den zum Ablauf der Flüssigkeit dienenden Zapfen war aussen ein Gewinde eingeschnitten. Die Montirung des Filters geschah nun einfach in der Weise, dass zunächst über den Zapfen eine weiche Gummischeibe geschoben, und dann das Filter in einen oben offenen, unten mit einer etwa $1.5^{\mathrm{cm}}$ weiten Bohrung versehenen Metallcylinder eingesetzt wurde, so dass der Auslaufzapfen durch die Oeffnung im Boden nach aussen ragte. Dann wurde mittels eines auf dem Gewinde des Zapfens laufenden Ringes das mit der Gummischeibe versehene untere Ende des Filters gegen den Boden des Cylinders so lange angezogen, bis ein flüssigkeitsdichter Abschluss nach aussen hergestellt war.

Ueber das freie Ende des Zapfens wurde alsdann ein Stückchen starkwandigen Kautschukschlauches gezogen, um demnächst die Verbindung mit der zur Aufnahme des Filtrates dienenden Saugflasche zu bewirken. Zum Zwecke der Sterilisation wurde das Metallgefäss mit Wasser gefüllt ${ }^{2}$

1 Diese Zeitschrift. Bd. X. Hft. 1. S. 145.

2 Die Kieselguhrkerzen vertragen im trockenen Zustande das Erhitzen im strömenden Dampf nicht, ohne zu springen. 
und dann der ganze Apparat zwei Stunden lang im strömenden Wasserdampf gehalten. Nach Beendigung der Sterilisation wurde das im Cylinder enthaltene Wasser ausgegossen und rasch das freie Ende des am Filterzapfen befestigten Kautschukschlauches über das Zulaufrohr der gleichzeitig sterilisirten Saugflasche geschoben. Letztere wurde mit der Wasserstrahlpumpe verbunden und damit war das Filter zum Gebrauch fertig. $\mathrm{Da}$ es sich in den Versuchen von Nordtmeyer herausgestellt hatte, dass eine Hauptursache der vorzüglichen Leistungsfähigkeit der Knieselguhrfilter in der leichten Regenerirbarkeit der Filterfläche durch Wischen liegt, so wurde von vornherein darauf Bedacht genommen, das Laboratoriumsfilter mit einer Reinigungsvorrichtung zu rersehen. $\mathrm{Zu}$ dem Zwecke erwies sich ein innen mit Loofah ausgekleideter federnder Messingring, welcher an zwei starken Führungsdrähten befestigt ron oben her über die Filterkerze geschoben werden konnte, als sehr zweckentsprechend. Wenn dieser Ring einige Male in Spiraltouren auf dem Filterkörper auf und abgeschoben wurde, so fand durch die enganliegende Loofahmasse eine ausgiebige Reinigung der filtrirenden Oberfläche statt.

Was nun die Resultate der Versuche anlangt, so ist vor Allem zu bemerken, dass jeder Kieselguhrkörper, sowohl der weniger durchlässigen, wie der durchlässigen Sorte, stets ein keimfreies Filtrat gab, mochte die zur Filtration benutze Probe auch noch so viel Bacterien enthalten. Selbst die kleinsten bis jetzt bekannten Bacterien, die Bacillen der Mäusesepticämie, werden, wie ich noch speciell feststellte, mit Sicherheit zurückgehalten. $O b$ das Filtrat keimfrei war, wurde in rigorosester Weise derart ermittelt, dass jedes Mal je 1 cem des Filtrates zu 10 Röhrchen mit 10 cem Bouillon zugefügt, und diese Bouillon im Brütofen bei $35^{\circ}$ mehrere Tage beobachtet wurde. Die Bouillon blieb ausnahmslos steril. Zu gleicher Zeit wurden auch noch öfter Gelatine- und Agarplatten vom Filtrat angelegt, welche ebenfalls dessen absolute Keimfreiheit bestätigten.

Nach diesen Resultaten schien es vor Allem wichtig die quantitatire Leistungsfähigkeit der Filter für stark bacterientrübe und eiweisshaltige Flüssigkeiten genauer festzustellen. Es stellte sich bald heraus, dass gerade in dieser Beziehung die Kieselguhrfilter den bis jetzt zur Gewinnung keimfreier Filtrate ausschliesslich angewandten Chamberlandfiltern bei Weitem überlegen sind.

Schon von rornherein leisten sie quantitativ bedentend mehr als z. B. Chamberlandfilter und versetzen sich bei weitem nicht so leicht wie diese. Dann aber kann man bei den Kieselguhrfiltern durch Wischen die filtrirende Oberfläche immer wieder freilegen und so während 
sehr langer Zeit durch ein und dasselbe Filter grosse Mengen Flüssigkeit filtriren. Bis zu einem gewissen Grade ist auch bei den Chamberlandfiltern durch Wischen die Leistungsfähigkeit zu regeneriren. Doch versagt das Mittel nach einiger Zeit, weil die viel härtere Porzellanmasse des Filters durch das Wischen mit Loofah nicht angegriffen wird, während bei den weichen Kieselguhrfiltern ausser dem aufgelagerten Schlick auch immer die mit feinsten Schlammtheilchen imprägnirte äusserste Schicht des Filters mit entfernt wird.

Die Chamberlandfilter sind in ihrer Leistungsfähigkeit übrigens durchaus nicht gleichmässig. Bei 9 Kerzen, welche ich untersuchte, schwankte die Durchlässigkeit für reines Leitungswasser bei einem Druck von $2 \frac{1}{2}$ Atmosphären zwischen 200 und $40^{\mathrm{cm}}$ pro Minute.

In den meisten Fällen betrug dieselbe 60 bis $80 \mathrm{~cm}$. . Bei allen nahm nach einige Zeit fortgesetzter Filtration, selbst reinen Leitungswassers, die Durchlässigkeit sehr rasch ab, innerhalb weniger Stunden bis fast auf Null.

\section{Vergleichende Filtrationsversuche mit sehr trüber fauler Bouillon}

ergaben (bei einem mittels Wasserstrahlpumpe hergestellten negativen Druck von $710^{\mathrm{mm}}$ ) folgende Resultate.

A. Chamberlandfilter.

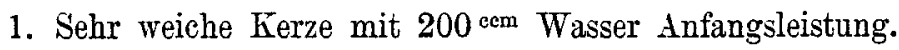

In den ersten 30 Minuten $450^{\mathrm{ccm}}$,

$"$, folg. $30 \quad, 180$,

" $" \quad 30 \quad$ ", 90,

$" \quad, \quad 30 \quad, \quad 40$,

120 Minuten $760^{\mathrm{ecm}}$.

Kerze 2 mit 100 eem Wasser Anfangsleistung.

In den ersten 30 Minuten $300^{\mathrm{cem}}$,

$"$ folg. $30 \quad, 160$,

$" \quad " \quad 30 \quad " \quad 80 "$

Kerze 3 mit $70 \mathrm{~cm}$ Wasser Anfangsleistung.

In den ersten 30 Minuten $290^{\mathrm{ccm}}$,

$"$ folg. 30 " 135,

$" \quad " \quad 30 \quad$ " $" 50 "$

" $" \quad 30 \quad$ " $15 "$

120 Minuten $490^{\mathrm{cem}}$. 
Nachdem die Leistung von Kerze 2 auf $80^{\mathrm{cem}}$ in 30 Minuten zurückgegangen war, wurde dieselbe kräftig mit Loofah gewischt und das Wischen während der weiteren Filtration alle Paar Minuten wiederholt. Dabei fiiltrirten:

$$
\begin{aligned}
& \text { In den ersten } 30 \text { Minuten } 180^{\mathrm{ccm}} \text { : } \\
& " \quad \text { folg. } 30 \quad, \quad 140 \text {, }
\end{aligned}
$$

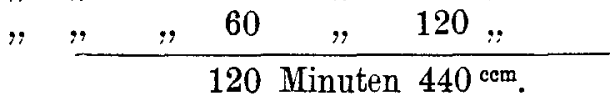

Kerze 3 ergab unter häufigem Wischen:

$$
\begin{aligned}
& \text { In den ersten } 30 \text { Minuten } 320^{\mathrm{cmm}} \text {. } \\
& " \text { " folg. } 30 \quad \text { " } 210 \text {.. } \\
& ", \quad, \quad 30 \quad, \quad 150, \\
& ", " \quad 30 \quad, \quad 140, \\
& 120 \text { Minuten } 820^{\mathrm{cm}} \text {. }
\end{aligned}
$$

Wie man sieht, geht auch in diesen Versuchen die Filtratmenge der Chamberlandkerzen schnell auf ein sehr geringes Maass herunter. Durch häufiges Wischen wird zwar die Leistungsfähigkeit etwas erhöht, doch nicht sehr bedeutend.

\section{B. Kieselguhrfilter.}

Ein solches von der wenig durchlässigen Sorte, ron der Grösse der Chamberlandfilter und etwa derselben Durchlăssigkeit für Wasser, wie Kerze 1, lieferte in den ersten 30 Minuten 660 und nach einmaligem kräftigen Wischen mit Loofah in den zweiten 30 Minuten $600^{\mathrm{ccm}}$ Filtrat.

Ganz bedeutend ausgiebiger sind aber die durchlässigen Kerzen.

Kerze 25 (von der Grösse der Chamberlandkerzen) ergab z. B. folgende Resultate:

A. Ohne Wischen.

In den ersten 30 Minuten $1350 \mathrm{~cm}$,

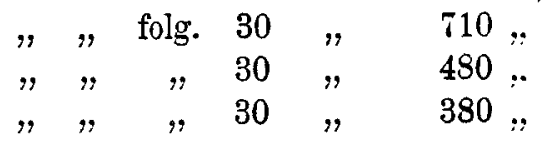

B. Unter häufigem Wischen.

In den ersten 30 Minuten $1930 \mathrm{~cm}$,

$"$ folg. $30 \quad, 1430,$.

$" \quad " \quad 30 \quad " \quad 1110$..

$" \quad, \quad 30 \quad " \quad 950$ :

In der folgenden Tabelle sind die Resultate der vergleichenden Versuche nochmals übersichtlich zusammengestellt. 


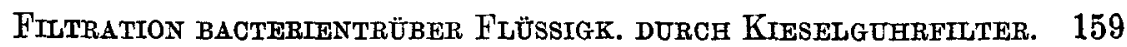

\begin{tabular}{|c|c|c|c|c|c|c|c|c|}
\hline \multicolumn{3}{|c|}{ Zeit } & $\begin{array}{l}\text { Chamber- } \\
\text { landkerze } \\
1\end{array}$ & $\begin{array}{c}\text { Chamber- } \\
\text { landkerze } \\
\mathbf{2}\end{array}$ & $\begin{array}{c}\text { Chamber- } \\
\text { landkerze } \\
\mathbf{3}\end{array}$ & $\begin{array}{c}\text { Chamber- } \\
\text { landkerze } 3 \\
\text { (unter } \\
\text { Wischen) }\end{array}$ & $\begin{array}{c}\text { Kieselguhr- } \\
\text { kerze } \mathbf{2 5}\end{array}$ & $\begin{array}{c}\text { Kieselguhr- } \\
\text { kerze } 25 \\
\text { (untor Wischen) }\end{array}$ \\
\hline 1. & $30 \mathrm{~N}$ & din. & 450 & 300 & 290 & 320 & 1350 & 1930 \\
\hline 2. & 30 & , & 180 & 160 & 135 & 210 & 710 & 1430 \\
\hline 3. & 30 & $"$ & 90 & $\stackrel{80}{(\text { unter Wisch })}$ & 50 & 150 & 480 & 1110 \\
\hline 4. & 30 & , & 40 & 180 & 15 & 140 & 380 & 950 \\
\hline 5. & 30 & , & - & 140 & - & - & - & - \\
\hline 6. & 30 & , & - & 120 & - & - & - & - \\
\hline 7. & 30 & " & - & 120 & - & - & - & - \\
\hline
\end{tabular}

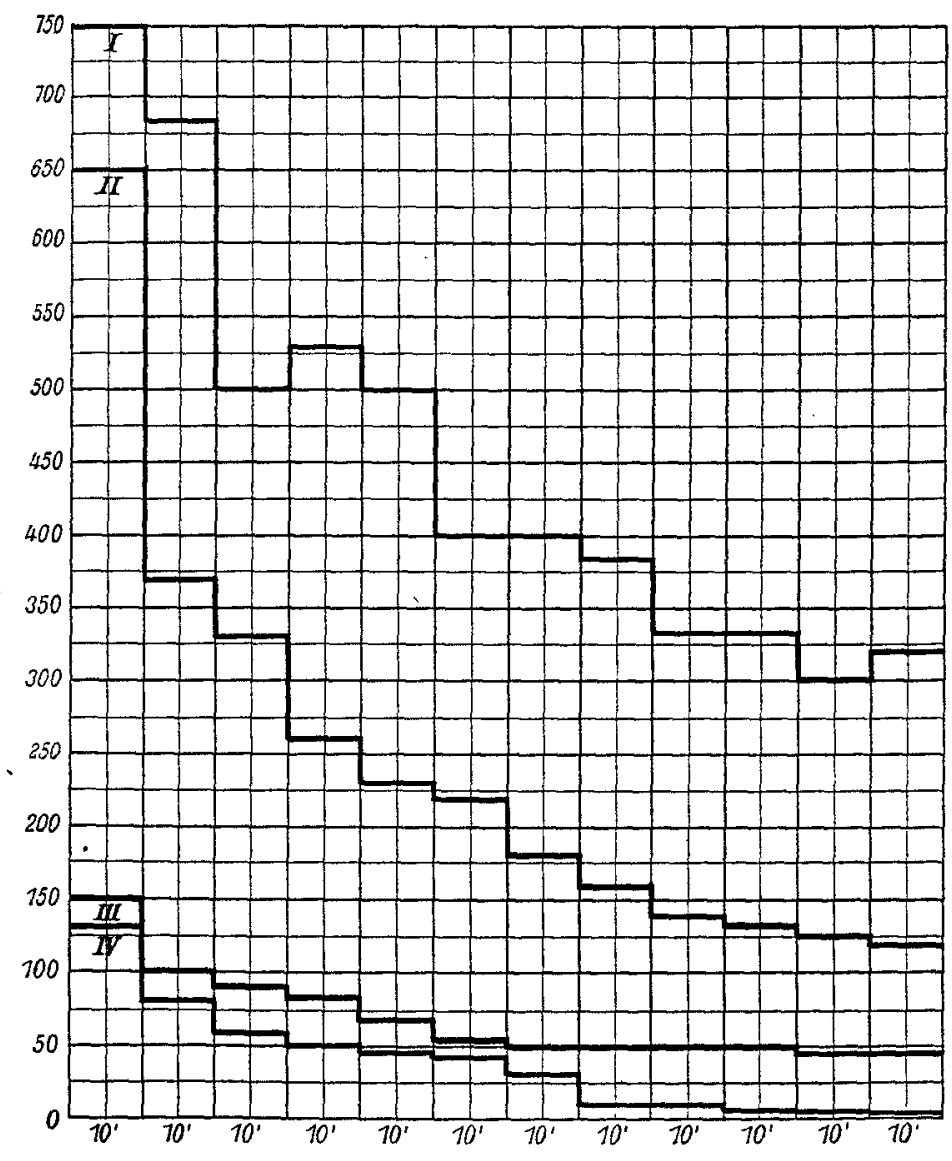

Fig. 1.

$I$ Kieselguhrkerze 25 ohne Wischen. II Kieselgnhrkerze 25 mit Wischen. III Chamberlandkerze II ohne Wischen. IV Chamberlandkerze II mit Wischen. 
Hierbei tritt die bedeutende Ueberlegenheit der Kieselguhrfilter sehr deutlich hervor. Im Anfange leisten dieselben mindestens das Vierfache wie die Chamberlandfilter; während im weiteren Verlaufe der Filtration das Verhältniss sich noch weit günstiger gestaltete. In den Versuchen, welche unter Wischen angestellt wurden, ergaben dann die Kieselguhrfilter mindestens die 7- bis 8-fache Menge Filtrat; in den Versuchen ohne Wischen steigt in der vierten halben Stunde das Verhältniss sogar bis auf 1:25. Noch deutlicher illustrirt wird die Ueberlegenheit der Kieselguhrfilter durch die beistehenden graphischen Darstellungen, von welchen Fig. 1 den Gang der Filtration bei Kieselguhr- und Chamberlandfiltern von $10 \mathrm{zu} 10$ Minuten angiebt, während Fig. 2 einen Vergleich der absoluten Filtratmenge während einer Stunde gestattet.

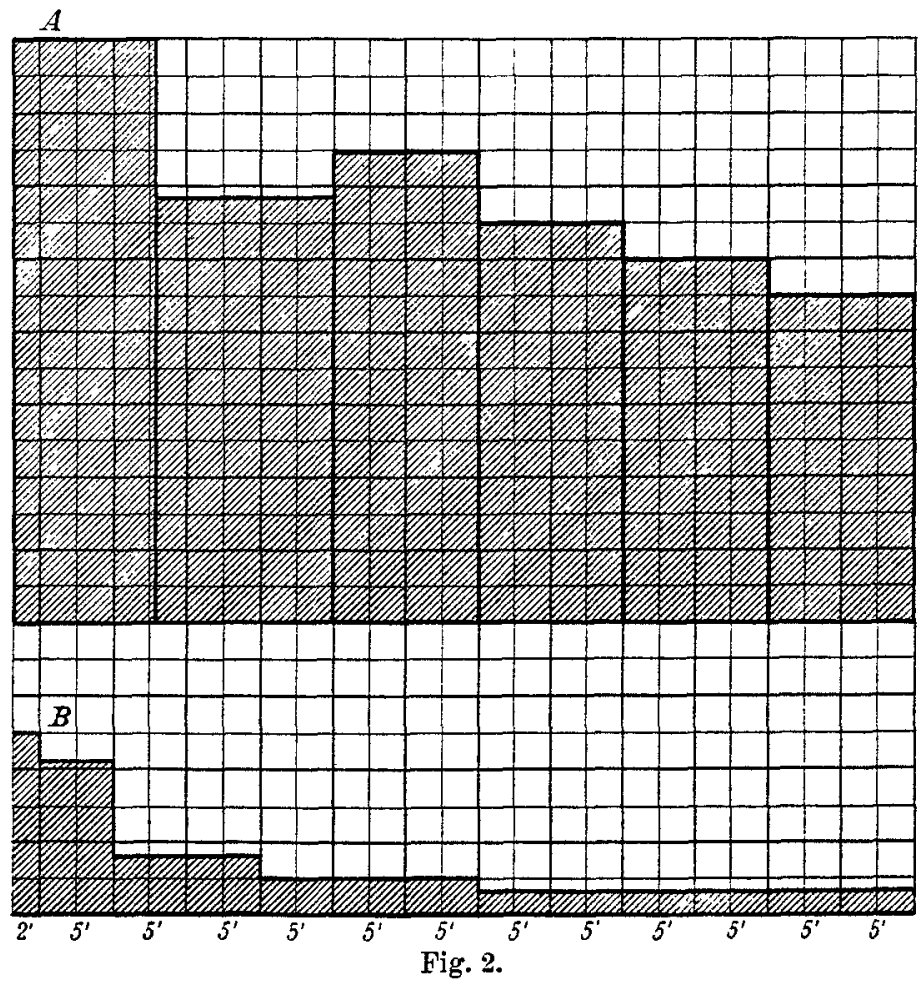

$A$ Kieselguhrfilter 25. $B$ Chamberlandfilter II.

Obenstehende Figuren zeigen, dass ein Kieselguhrfilter im Verlaufe längerer Zeit etwa die zehnfache Filtratmenge wie ein Chamberlandfilter gleicher Grösse liefert.

Grössere Kerzen, mit $2^{1} / 2$ mal so grosser Oberfläche, wie die Chamberlandkerzen ergaben entsprechend grössere Mengen Filtrat. 
Filtration bacterientrü̈ber FLÜssigk. DURCh hígselguHrfitter. 161

So z. B. eine Kerze von der weniger durchlässigen Sorte Nr. 23.

In den ersten 20 Minuten $860^{\mathrm{ccm}}$,

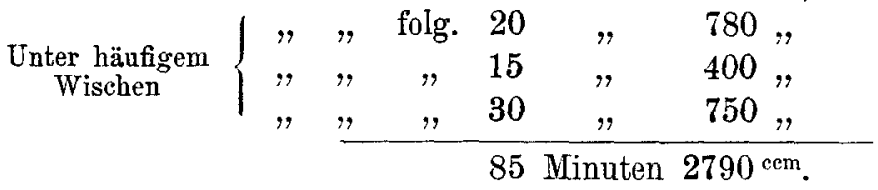

Durchlässige Kerze 28a.

$$
\begin{aligned}
& \text { In } 1 \text { Minute } 300 \mathrm{ccm} \text {, } \\
& \text { "folg. } 1 \text { " } 200 \text {, } \\
& \text { " , } 3 \text { Minuten } 260 \text {. } \\
& ", 2 \quad, \quad 100, \\
& \begin{array}{c}
\text { Unter ofterem } \\
\text { Wischen }
\end{array}\left\{\begin{array}{llllr}
" & " & 2 & " & 200 " \\
" & " & 2 & " & 100 " \\
" & " & 10 & \eta & 680 "
\end{array}\right.
\end{aligned}
$$

Durchlässige Kerze 28 b.

$$
\begin{aligned}
& \text { In den ersten } 6 \text { Minuten } 900 \mathrm{ccm} \text {, }
\end{aligned}
$$

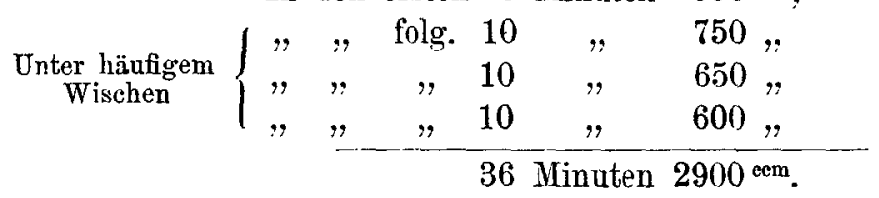

\section{Versuche mit eiweisshaltigen Flüssigkeiten.}

A. Versuche mit Blutserum.

Ziemlich stark blutiges frisches Blutserum.

Chamberlandkerze 1 liefert in 30 Minuten $200^{\mathrm{cem}}$. Dann ist aber die Leistung auch fast auf Null zurückgegangen.

Chamberlandkerze 3 liefert in 2 Stunden nur $130 \mathrm{~cm}$.

Kieselguhrfilter 28a ergiebt unter ofterem Wischen in 30 Minuten $800 \mathrm{~cm}$ klares keimfreies Serum bei dauernd gleich guter Leistung.

Kieselguhrfilter 25 (klein) ergiebt unter öfterem Wischen in 30 Iinuten $400^{\mathrm{cm}}$ klares Blutserum bei dauernd gleich guter Leistung.

Auch stark faules Blutserum filtriren die Filter rasch klar und bacterienfrei; z. B.

Filter 28 a. In 25 Minuten $680^{\mathrm{cm}}$ bei dauernd gleich guter Leistung.

Filter $28 \mathrm{~b}$. In 1 Stunde $=950 \mathrm{~cm}$. 
162 H. BitTeR: Filtration BaCterientrüber Flüssigkeiten U. s. w.

\section{B. Versuche mit Milch.}

Aus frischer Milch, welche durch die Chamberlandfilter und die dichteren Kieselguhrfilter gar nicht filtrirt werden kann, schied

die Kerze $28 \mathrm{a}$ in 120 Minuten $300 \mathrm{~cm}$,

die Kerze $28 \mathrm{~b}$ in 120 Yinuten $280^{\mathrm{cm}}$ klares fett- und bacterienfreies Serum ab.

Geronnene Milch kiann sehr viel leichter tiltrirt werden.

Kerze 28 a lieferte in 35 Minuten $500 \mathrm{~cm}$ klares keimfreies Serum bei dauernd gleich guter Leistung.

Aus den mitgetheilten Versuchen ist die vorzügliche Brauchbarkeit der Kieselguhrilter tür Laboratoriumszwecke ohne Weiteres ersichtlich. Filtration von Culturen in flüssigem Nährsubstrat behufs Isolirung von Stoffwechselproducten der Bacterien lässt sich mittels derselben in kürzester Zeit ohne Mühe in jeder Quantität bewirken. Von ganz besonderem Vortheil sind die Kieselguhrfilter ferner für die Gewinnung steriler eiweisshaltiger Nährsubstrate, welche sich bis dahin eigentlich nur auf dem umstïndlichen Wege der hïufig wiederholten Erhitzung auf eine Temperatur von 55 bis $60^{\circ}$ zuverlässig keimfrei gewinnen liessen. Mittels einer Kieselguhrkerze grösserer Art lassen sich in einer Stunde mindestens $1000^{\mathrm{cm}}$ zuverlässig keimfreies, vorzügliches Blutserum gewinnen. 